\title{
Evaluation of Knowledge, Attitude and Practice about the Antibiotics Prescription
}

\author{
Monika Allaudin Khoja*, KS Poonacha, Anshula Deshpande, Seema Bargale, Rameshwari Raol and \\ Parth Joshi
}

Dental College and Hospital, Waghodia Road, Vadodara, Gujarat, India

Correspondence should be addressed to Monika Allaudin Khoja, monikakhoja@gmail.com

Received: August 23, 2020; Accepted: September 09, 2020, Published: September 16, 2020

\section{KEYWORDS}

Antibiotics; Knowledge; Practice; AAPD guidelines

\section{INTRODUCTION}

Antibiotics are used for the management of active infectious diseases and/or to prevent the systemic spread of infection. Antibiotic therapy for orofacial infections can achieve excellent benefits in selected clinical situations but should not be the primary treatment modality for orofacial infections. There is serious and global problem of antibiotic abuse and there is a growing consensus to urgently develop new strategies for prevention of resistance of bacteria to antibiotics. To prevent misuse of antibiotics, dentists need to know the indications and contraindications for prescribing them, proper dosing schedules, and the risk of allergic and toxic adverse reactions, super infections, and development of antibiotic-resistant organisms.

\section{$\underline{\text { AIM }}$}

To evaluate knowledge, attitude and practice about the use of antibiotics among BDS students and interns.

\section{METHOD}

A total of 166 final year students and interns studying at K.M. Shah Dental College and Hospital, Vadodara were included in the study out of which 97 were final year students and 69 were interns.

A structured questionnaire of 20 Questions pertaining to the use of antibiotics were given to the participants.

Validation of the questionnaire had been done by five subject experts and 20 participants. The data obtained was later validated by the statistician.

Few questions were as follows.

Questions about knowledge and attitude:

1. Antibiotics are effective against,
A. Bacterial Infection
B. Viral Infection
C. Both
D. None of the above

2. 8-years-old male patient reports to you (No systemic illness present), in which dental conditions, you will prescribe the antibiotics?
A. Chronic Irreversible pulpitis
B. Ellis Class II fracture i.r.t.21

Citation: Monika Allaudin Khoja, Evaluation of Knowledge, Attitude and Practice about the Antibiotics Prescription. Case Rep Dent Sci 1(2): 35-39. 
C. Dentoalveolar Abscess

D. All of above

3. A 7-years-old Male patient reports to you (weight $20 \mathrm{~kg}$ ), the dosage of Amoxicillin Antibiotic would be?
A. Tab.125mg TDS - For 5days
B. Tab.250mg TDS - For 5days
C. Tab.500mg TDS - For 5days
D. Tab.625mg TDS - For 5days

4. By giving prophylactic antibiotics in medically compromised patients what all complications can be prevented in Pediatric Patients?
A. Dry socket
B. Infective endocarditidis
C. Bacteremia
D. All of above

5. For Allergic testing, what is being done in Pediatric patients by you?
A. Injecting small amount of drug intradermally
B. Bacterial Culture
C. Both
D. Not required

6. According to AAPD guidelines (2016), in case of odontogenic Infection the empirical choice of drug and adjuvant drug for anaerobic infection are (patient is not allergic to penicillin)
A. Penicillin alone is sufficient
B. Penicillin + Metronidazole
C. Penicillin + Ornidazole
D. Penicillin + Anti-histamine

7. What all guidelines were reviewed to formulate AAPD guidelines (2016), for antibiotic prophylaxis?
A. American Heart Association
B. AAOS
C. American Dental Association
D. All of above

8. As an intra-canal medicament ( $2 \mathrm{M}$ paste) in pediatric dental patient, what should be placed?
A. Ciprofloxacin + Metronidazol
B. Amoxicillin + Metronidazol
C. Clindamycin + Metronidazol
D. Amoxicillin + Clindamycin

9. An 8-years-old male patient, presents with an orofacial infection and you prescribe a course of antibiotics and given an appointment after the course is completed. The patient returns to you and there is not much improvement, patient has fever, malaise, weakness and lethargy. What would you prefer to do in the following situation?

A. Again Antibiotics will be prescribed

B. Antibiotics will be changed

C. Dose of antibiotics will be changed

D. Patient will be referred to Pediatrician for medical evaluation

10. A male pediatric patient reports to you with Primary Herpetic Gingivo Stomatitis, what drugs can be prescribed?
A. Antibiotics
B. Antivirals
C. Antacids
D. None of the above

Questions about Practice and Attitude:

1. Do you advice the Pre and Pro-biotics in Pediatric Dentistry?
A. Yes
B. No

2. Have heard about the word 'Drug Resistance'?
A. Yes
B. No

3. Do you follow the latest 'AAPD guidelines' for prescribing Antibiotics in Pediatric patients?
A. Yes
B. No

4. Do you enquire from your patient about whether he/she has taken a course of antibiotics in the past 1 week before prescribing antibiotics?
A. Yes
B. No

5. Self-medication with antibiotics by patients to get relief from dental pain may be responsible for antibiotic resistance?
A. Yes 
B. No

6. Do you calculate the dosage of the drugs according to the age and weight of the child?
A. Yes
B. No

7. When do you ask the patient to consume antibiotics?
A. Before meal
B. After meal

8. In the case of medically compromised pediatric patient, initially what will you do?
A. Refer the patient to pediatrician
B. Prescribe the antibiotics

9. Have you ever noticed any adverse drug reaction in the Pediatric Patients?
A. Yes
B. No

10. Do you prescribe antacids along with antibiotics in Pediatric patients?
A. Yes
B. No

\section{RESULTS}

The chi square test was used to evaluate the knowledge between both the groups, $\mathrm{p}$ value was statistically significant i.e. $\mathrm{p}$ value was $<0.001 \%$ in questions regarding dose calculation, allergy testing, placement of intracanal medicament and antibiotic prescription other than pulpal diseases.

The chi square value was 22.376, 5.826, 8.660, 29.073, 17.825 and 121.154 respectively. $\mathrm{p}$ value was not statistically significant in questions regarding effectiveness of antibiotic, indications in dental conditions, antibiotic combinations and formulation of American academy of paediatric dentistry.

$86.8 \%$ of final tear students and $98.5 \%$ of interns were aware about antibiotic resistance and they believe that self-medication is responsible for the same.

$92.3 \%$ of final years and $96.9 \%$ of interns don't follow the latest AAPD guidelines and they don't calculate drug dosage according to age and weight in every patient.

In the case of medically compromised patients, $65.9 \%$ of final years and $76.9 \%$ of interns prefer paediatric reference first.

More than $95 \%$ of final years and inters have not notice any adverse drug reaction and they prescribe antacids along with antibiotics.

\section{CONCLUSION}

Overall the knowledge of interns pertaining to antibiotic prescription was more than final year students but there was no significant difference. The knowledge regarding the use and effectiveness of antibiotics was good among both the groups, but the knowledge regarding dose calculation and use of pre and pro antibiotic was poor in both groups. It can be concluded that the prescribing practices of final year students and interns can be improved by increasing awareness regarding antibiotic prescription by following the latest standard guidelines for pediatric patients.

\section{REFERENCES}

1. Adelsperger J, Campbell J, Coates D, et al. (2000) Early soft tissue pathosis associated with impacted third molars without pericoronal radiolucency. Oral Surgery, Oral Medicine, Oral Pathology oral radiology, and endodontics 89(4): 402-406.

2. National Institute for Clinical Excellence. Guidance on the extraction of wisdom teeth. London: NICE. 
http://www.tridhascholars.org | December-2020

3. Adeyemo W (2006) Do pathologies associated with impacted lower third molars justify prophylactic removal? A critical review of the literature. Oral Surgery, Oral Medicine, Oral Pathology, Oral Radiology, and Endodontics 102(4): 448452.

4. Baumgart C, Lauxen I, Filho M, et al. (2007) Epidermal growth factor receptor distribution in pericoronal follicles: Relationship with origin of odontogenic cysts and tumors. Oral Surgery, Oral Medicine, Oral Pathology, Oral Radiology, and Endodontics 103(2): 240-245.

5. Baykul T, Saglam AA, Aydin U, et al. (2005) Incidence of cystic changes in radiologically normal impacted lower third molar follicles. Oral Surgery, Oral Medicine, Oral Pathology, Oral Radiology, and Endodontics 99(5): 542-545.

6. Alattar M, Baughman RA, Collett WA (1980) A survey of panoramic radiographs for evaluation of normal and pathologic findings. Oral Surgery, Oral Medicine, Oral Pathology 50(5): 472-478.

7. Bernick S (1949) Dentigerous cysts of the jaw. Oral Surgery, Oral Medicine, Oral Pathology 2(7): 914-921.

8. Bruce RA, Frederickson GC, Small GS (1980) Age of patients and morbidity associated with mandibular third molar surgery. Journal of the American Dental Association 101(2): 240-245.

9. Curran AE, Damm DD, Drummond JF (2002) Pathologically significant pericoronal lesions in adults: Histopathologic evaluation. Journal of Oral Maxillofacial Surgery 60(6): 613-617.

10. Leitner C, Hoffmann J, Krober S, et al. (2007) Low grade malignant fibrosarcoma of the dental follicle of an unerupted third molar without any clinical evidence of any follicular I Li- lesion. Journal of Cranio-Maxillofacial Surgery 35(1): 48-51.

11. Daley TD, Wysocki GP (1995) The small dentigerous cyst; A diagnostic dilemma. Oral Surgery, Oral Medicine, Oral Pathology, Oral Radiology, and Endodontics 79(1): 77-81.

12. Eliasson S, Heimdahl A (1989) Pathological changes related to long term impaction of third 9 , molars: A radiographic study. International Journal of Oral and Maxillofacial Surgery 18(4): 210-212.

13. Rakprasitkul K (2001) Pathologic changes in the pericoronal tissues of unerupted third molars. Quintessence International 32(8): 633-638.

14. Girod SC, Gerlach KL, Krueger G (1993) Cysts associated with long-standing impacted third molars. International Journal of Oral and Maxillofacial Surgery 22(2): 110-112.

15. Glosser JW, Campbell JH (1999) Pathologic change in soft tissue associated with radiographically normal third molar impactions. The British Journals of Oral \& Maxillofacial Surgery 37(4): 259-260.

16. Knutsson K, Brehmer B, Lysell L, et al. (1996) Pathoses associated with mandibular third molars subjected to removal. Oral Surgery, Oral Medicine, Oral Pathology, Oral Radiology, and Endodontics 82(1): 10-17.

17. Mercier P, Precious D (1992) Risks and benefits of removal of impacted third molars. A critical review of the literature. International Journal of Oral \& Maxillofacial Surgery 21(1):17-27.

18. Mesgarzadeh A, Esmailzadeh M, Shahamfar M (2008) Pathosis associated with radiographically normal follicular tissue in third molar impactions: A clinicopathological study. Indian Journal of Dental Research 19(3): 208-212.

19. (1980) National Institute of Health consensus development conference for removal of third molars. Journal of Oral Surgery 38(3): 235-236.

20. Nordenram A, Hultin M, Kiellman O, et al. (1987) Indications for surgical removal of the mandibular third molars. Study of 2,630 cases. Swedish Dental Journal 11(1-2): 23-29. 
21. Osborn TP, Fredrickson GC, Small TA, et al. (1985) A prospective study of complications related to mandibular third molar surgery. Journal of Oral \& Maxillofacial Surgery 43(10): 767-768.

22. Severin I, von Wowern N (1990) A radiographic four-year follow-up study of asymptomatic mandibular third molars in young adults. International Dental Journal 40(1): 24-30.

23. Shear M (1983) Cysts of oral regions ( $2^{\text {nd }}$ Edn.), Bristol, England: John Wright PSG 56-75.

24. Van-der Linden W, Cleaton-jones P, Lownie M (995) Diseases and lesions associated with third molars Review of 1001 cases. Oral Surgery, Oral Medicine, Oral Pathology, Oral Radiology, and Endodontics 79(2): 142-145.

25. Yildririum G, Hanife A, Mihmanli A, et al. (2008) Pathologic changes in soft tissues associated with asymptomatic impacted third molars. Oral Surgery, Oral Medicine, Oral Pathology, Oral Radiology, and Endodontics 106(1): 14-18.

26. Slater LJ (2008) Comments on "Pathologic changes in soft tissues associated with asymptomatic impacted third molars". Oral Surgery, Oral Medicine, Oral Pathology, Oral Radiology, and Endodontics 107(1): 5. 